\title{
Ugi Reaction of Natural Amino Acids Promoted by $\mathrm{NbCl}_{5}$
}

\author{
Milenna M. Sena, ${ }^{1}$ Carlos Kleber Z. Andrade, ${ }^{2}$ Rafael O. Rocha ${ }^{1 *}$
}

1 Universidade de Brasília Campus Universitário Darcy Ribeiro, Insituto de Química, Laboratório de Isolamento e Transformação de Moléculas Orgânicas (LITMO) - Caixa Postal: 4478, CEP: 70910-900.

2 Universidade de Brasília Campus Universitário Darcy Ribeiro, Insituto de Química, Laboratório de Química Metodológica e Orgânica Sintética (LaQMOS) - Caixa Postal: Caixa Postal: 4478, CEP: 70910-900.

*e-mail corresponding author: rafaelrocha@unb.br

Keywords: Diastereoselectivity, Ugi Reaction, Amino acids, Niobium pentachloride

\section{INTRODUCTION}

Multicomponent Reactions (MCR) are useful reactions to obtain complex products by a simple mixture of 3 or more reactants. ${ }^{1}$ Classic Ugi reaction (4-UCR) involves a mixture of an amine, aldehyde, isocyanide and a carboxylic acid giving peptoides as products. Some modifications on the components such as the use of amino acids and Lewis acids like titanium (IV) chloride have been reported to induced stereoselectivity in good ratio. ${ }^{2}$

Niobium (V) pentachloride have been reported as an efficient Lewis acid to promote several organic reactions. ${ }^{3}$ This led us to investigate the use of $\mathrm{NbCl}_{5}$ as Lewis acid and its ability to induce the new chiral center formed in the Ugi reaction using natural amino acids, aldehyde, isocyanide and methanol as a forth component.

\section{RESULTS AND DISCUSSION}

A mixture of $1 \mathrm{mmol}$ of amino acid and $1 \mathrm{mmol}$ of aldehyde in anhydrous methanol was stirred for 30 minutes at room temperature. After this time, $1 \mathrm{mmol}$ of tert-butylisocyanide and $0.3 \mathrm{mmol}$ of $\mathrm{NbCl}_{5}$ were added and stirred for $72 \mathrm{~h}$ (Scheme 1).

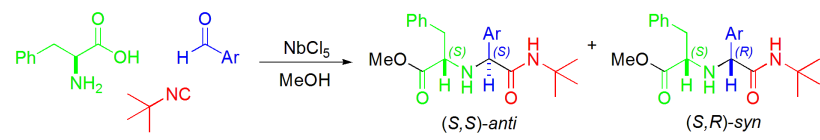

Scheme 1. Ugi reaction of amino acids mediated by $\mathrm{NbCl}_{5}$.

The products were isolated by column chromatography and the yields ranged from 40 to $50 \%$ in a moderate diastereoselectivity $(3-4: 1)$ in favor of the $(S, S)$-isomer (Table 1 ).

Table 1. Results of Modified Ugi Reactions using $\mathrm{NbCl}_{5}$.

\begin{tabular}{|c|c|c|c|}
\hline Entry & Ar & Ratio $(\boldsymbol{S}, \boldsymbol{S}):(\boldsymbol{S}, \boldsymbol{R})^{\text {a }}$ & Yield (\%) $^{\mathbf{b}}$ \\
\hline $\mathbf{1}$ & 3- $\mathrm{NO}_{2} \mathrm{Ph}$ & $4: 1$ & 40 \\
$\mathbf{2}$ & $4-\mathrm{NO}_{2} \mathrm{Ph}$ & $3: 1$ & 42 \\
$\mathbf{3}$ & $4-\mathrm{Cl}-\mathrm{Ph}$ & $3: 1$ & 50 \\
\hline
\end{tabular}

a) Calculated by ${ }^{1} \mathrm{H}-\mathrm{NMR}$ spectroscopic data from crude product.

b) After purification on column chromatography.

$14^{\text {th }}$ Brazilian Meeting on Organic Synthesis $-14^{\text {th }}$ BMOS - September 01-05, 2011-Brasilia, Brazil
Initial results were not satisfactory and could be attributed to the complexation of niobium and isocyanide, decreasing its nucleophilicity and leading to moderate yields.

The reaction using amino ester instead of amino acids was also investigated in an attempt to increase the product yields (Scheme 2).

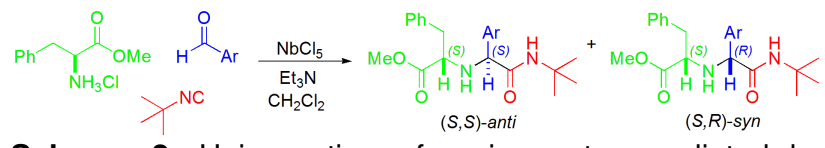

Scheme 2. Ugi reaction of amino ester mediated by $\mathrm{NbCl}_{5}$.

The reaction was carried out in dry dichloromethane and an equimolar amount of $\mathrm{Et}_{3} \mathrm{~N}$. In this conditions, the product was isolated in only $35 \%$ yield.

Several modifications are being made to increase the yields and diastereoselectivities such as changes in the Lewis acids, solvents, temperatures and substrates.

\section{CONCLUSION}

Preliminary results showed the efficiency of $\mathrm{NbCl}_{5}$ as Lewis Acid despite the moderate yields and poor selectivity. Some modifications on the methodology are being investigated to improve both yields and diastereoselectivities.

\section{ACKNOWLEDGEMENTS}

IQ-UnB, CAPES, FINEP CT-INFRA 0970/01

\section{REFERENCES}

${ }^{1}$ Domling, A. Chem. Rev. 2006, 106, 17.

${ }^{2}$ Godet, T.; Bonivn, Y.; Vincent, G.; Merle, D.; Thozet, A.; Ciufolini, M. A. Org. Lett. 2004, 6, 3281.

3 a) Andrade, C. K. Z.; Rocha, R. O. Mini Rev. Org. Chem. 2006, 3, 271. b) Andrade, C. K. Z. Curr. Org. Synth. 2004, 1, 333. 